\title{
Modeling the formation and dynamics of cortical waves induced by cholinergic modulation
}

\author{
James P Roach ${ }^{1 *}$, Eshel Ben-Jacob ${ }^{2,3}$, Leonard M Sander ${ }^{4}$, Michal R Zochowski ${ }^{1,4,5}$ \\ From 24th Annual Computational Neuroscience Meeting: CNS*2015 \\ Prague, Czech Republic. 18-23 July 2015
}

States of arousal, or consciousness with the brain are regulated largely by the neurotransmitter acetylcholine (ACh). Specifically, ACh is likely responsible for the transition between slow wave sleep (SWS; where ACh is absent) and rapid eye movement sleep or waking states (where ACh is high). Patterns of neural activity within the cerebral cortex corresponding to these states are markedly different. During SWS there are traveling waves of intense activity in the cortex while in other states locally organized stationary patterns occur [1]. From a functional perspective, stationary patterns are likely to be important for working memory and attention dynamics while traveling waves could lead to synaptic renormalization [2]. The mechanism for how changes on the cellular level are translated to patterns on the network level is not understood. In this work we give a model for the action of ACh on a network of neurons of the Hodgkin-Huxley type with a current that is regulated by $\mathrm{ACh}$ that induces spike-frequency adaptation (SFA) [3]. The cells are coupled in a center-surround scheme. When SFA is minimal (such as in waking or REM sleep state, high $\mathrm{ACh}$ ) patterns of activity are localized and easily pinned to regions defined by enhanced recurrent excitation. Increasing the level SFA is present

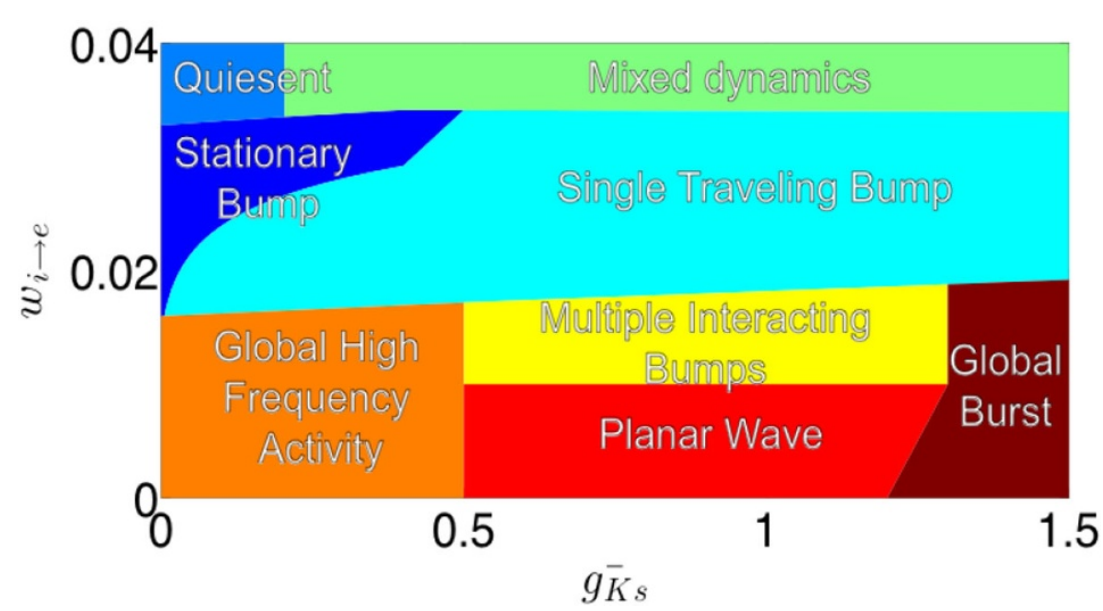

Figure 1 An illustration of the dynamics sampled by scannig inhibitory strength, $\left(\mathbf{w}_{\mathbf{i}} \mathbf{e}\right)$, and $\mathbf{g}_{\mathbf{k s}}$. In this model $g_{K_{s}}$ is increased to simulate decreasing ACh levels. In a general sense, the spatial scope of activity is determined by the excitatory/ inhibitory balance, and the temporal scope of activity is determined by the strength of SFA.

\footnotetext{
* Correspondence: roachjp@umich.edu

${ }^{1}$ Neuroscience Graduate Program, University of Michigan, Ann Arbor, MI, 48109, U.S.A

Full list of author information is available at the end of the article
} 
(by increasing $\mathrm{ACh}$ ), traveling waves of activity naturally arise. Depending on the strength of inhibitory coupling within the network, SFA is able to induce a wide variety of dynamical regimes (Figure 1). We present a detailed mechanism that shows that the level of inhibition sets the spatial extent of network activity and that SFA defines the temporal scope, which is directly modulated by $\mathrm{ACh}$ in the model. These model calculations give unique insights into the role and significance of $\mathrm{ACh}$ in determining patterns of cortical activity and functional differences arising from these patterns.

\section{Acknowledgements}

This work is supported by the NSF Graduate Research Fellowship Program under Grant No. DGE 1256260 (JPR), the Tauber Family Funds and the Maguy-Glass Chair in Physics of Complex Systems at Tel Aviv University (EBJ), NSF Center for Theoretical Biological Physics Grants PHY-1427654 and NSFMCB-1214457 (EBJ), NSF CMMI 1029388 (MRZ), and NSF PoLS 1058034 (MRZ 1\& LMS).

\section{Authors' details}

${ }^{1}$ Neuroscience Graduate Program, University of Michigan, Ann Arbor, MI, 48109, U.S.A. ${ }^{2}$ School of Physics and Astronomy, Tel-Aviv University, Tel Aviv, 69978, Israel. ${ }^{3}$ Center for Theoretical Biological Physics, and Department of Biochemistry and Cell Biology, Rice University, Houston, TX, 77005, USA

${ }^{4}$ Department of Physics \& Center for Studies of Complex Systems, University of Michigan, Ann Arbor, Ml, 48109, USA. ${ }^{5}$ Biophysics Program, University of Michigan, Ann Arbor, MI, 48109, USA.

Published: 18 December 2015

\section{References}

1. Massimini M, Huber R, Ferrarelli F, Hill S, Tononi G: The Sleep Slow Oscillation as a Traveling Wave. Journal of Neuroscience 2004, 24:6862-6870.

2. Tononi G, Cirelli C: Sleep and synaptic homeostasis: a hypothesis. Brain Research Bulletin 2003, 62:143-150.

3. Stiefel KM, Gutkin BS, Sejnowski TJ: The effects of cholinergic neuromodulation on neuronal phase-response curves of modeled cortical neurons. J Comput Neurosci 2008, 26:289-301.

doi:10.1186/1471-2202-16-S1-P304

Cite this article as: Roach et al:: Modeling the formation and dynamics of cortical waves induced by cholinergic modulation. BMC Neuroscience 2015 16(Suppl 1):P304.

\section{Submit your next manuscript to BioMed Central} and take full advantage of:

- Convenient online submission

- Thorough peer review

- No space constraints or color figure charges

- Immediate publication on acceptance

- Inclusion in PubMed, CAS, Scopus and Google Scholar

- Research which is freely available for redistribution

Submit your manuscript at www.biomedcentral.com/submit 